UDK: 330.101.541(497)

DOI: $10.2478 / j c b t p-2018-0018$

Journal of Central Banking Theory and Practice, 2018, 2, pp. 187-202

Received: 27 July 2017; accepted: 27 December 2017

Aneta Krstevska*

\section{Real Convergence of Western Balkan Countries to European Union in view of Macroeconomic Policy Mix ${ }^{1}$}

\begin{abstract}
Western Balkan (WB) countries have a clear orientation towards the European Union (EU), all of them currently being candidate or potential candidate countries. Moreover, the EU is an important trading partner of the WB economies, therefore, there is a recognizable need for convergence of this region towards the EU economy. The real convergence is a rather slow process and the WB region is still lagging behind the EU. This paper explores the catch up of the WB region during the global crisis that severely hit the EU economy, trying to identify potential changes in the convergence pace. In addition, this work makes a joint overview of the nominal and real convergence processes as well as the convergence of the general macroeconomic indicators of the WB countries to the EU, taking them as complementary and mutually self-supporting processes.
\end{abstract}

Key words: convergence, catch up, crisis, panel.

JEL classifications: F15, O11, O57.

\section{Introduction}

Western Balkan (WB) countries have been gradually converging to the European Union (EU) throughout the tran-

1 These views are those of the author and do not reflect the views of any institution.
${ }^{*}$ National Bank of the Republic of Macedonia, Skopje, Macedonia

Email:

aneta.krstevska@gmail.com 
sition period. However, due to different reasons, including transitional issues, macroeconomic factors as well as internal and external shocks, the real convergence of the WB region to the EU average is relatively slow. The recent global crisis created a specific environment for the convergence process of the WB economies.

From the theoretical viewpoint, real convergence is a necessary precondition for optimal currency zone, as similar economic structure and flexible product markets should diminish asymmetric shocks. Additionally, the entrance in the euro area requires nominal convergence measured through several indicators (inflation, interest rates, exchange rate), as adequate economic conditions for the maintenance of price stability and the coherence of the euro area. This requires the convergence of macroeconomic policy and main macroeconomic indicators. In practice, nominal convergence and real convergence seem to support each other. Without nominal convergence - maintenance of the main macroeconomic indicators on sustainable level - economic growth may suffer, affecting the pace of real convergence. At the same time, a higher degree of real convergence makes nominal convergence easier. This paper will focus on the WB countries' nominal and real convergence, as well as convergence of the main macroeconomic indicators to the EU and their mutual interlinkages.

The WB countries included in this analysis are the following five countries: Albania, Bosnia and Herzegovina, Macedonia, Montenegro, and Serbia. The first part of the paper gives a literature overview, followed by the section with stylized facts on the conversion process of the analysed countries. In the next section, the data and methodology for the empirical research have been explained, followed by the results and concluding remarks.

\section{Literature overview}

When looking into EU convergence, there are many papers on the convergence of the new member states relative to the core members, but still not so many papers on the convergence of the WB countries towards the EU. The usual approach to the convergence analysis is the beta and sigma convergence (Barro and Sala-i-Martin, 1992). The beta coefficient points to the relationship between the growth rate and the income level and refers to country specific factors behind convergence (so-called absolute convergence). Negative beta coefficient means that a poorer country moves towards richer countries and decreases the existing gap. The sigma convergence measures the fluctuations of GDP per capita disparity relative to richer countries. 
Marelli and Signorelli (2015) focused on the convergence in the EU during the crisis period. They analysed the absolute beta convergence in GDP per capita within the EU member states and they found that there was a significant convergence in the crisis period, probably because the crisis made some impact on the richer countries. When discussing the causality between the nominal and real convergence in the framework of the optimal currency area and the Maastricht criteria, the authors noted that there were expectations in the EU that the countries could be rewarded by the gains in the monetary union, including disinflation, lower interest rates and transaction costs, lesser uncertainty, reinforced competition. On the other hand, the authors argued that some countries faced consequences because their economic growth has been impaired by the stringency of the nominal conditions. However, besides discussing the austerity policies during the crisis, they noted that the economic growth has not been uniform across the EU and besides the catch up of the new member states, some of the old members exhibited low growth rates, considering weak productivity growth and a lack of structural reforms. According to Bastidon et al. (2016), the major weaknesses are quasi unchanged in the euro area: first, public debt level and inadequate tax harmonization, and second consideration must be given on how to conciliate a coherent monetary policy and the new banking intermediation frameworks in times of high financial strains. Shehovic (2015) noted that the pre-crisis mechanism for the fiscal policy coordination failed to maintain fiscal discipline, ensure sufficient fiscal space and/or provide automatic stabilizers operation in crisis conditions, which induced the need for reforms (Six-Pack).

Halmai and Vasary (2010) pointed to the difference between the catch-up rates and the convergence, explaining that the catching-up is "the distance to be travelled" and the convergence is the measure of progress. They found that the catch up rate of the ten new member states of the EU significantly increased after their accession in the EU in the period 2004-2008, considering faster growth rates in this period. Regarding sigma convergence, their analysis has shown that after the EU enlargement in 2004, disparities between the EU member states were much higher.

Stanisic (2016) tested the existence and speed of income convergence of the WB countries relative to the $\mathrm{EU}$ and found that despite the achieved convergence in the pre-crisis period, the global crisis outbreak interrupted this process. According to the sigma concept, there was convergence between the WB countries and EU-15 after 2000 that lasted until the crisis outbreak. Stanisic (2016) also found that the convergence of the new member states to the EU-15 had been faster up to the crisis, and after a short interruption, it picked up pace in 2011. According to beta concept, the WB countries and the new member states in period 1993-2015 
experienced convergence to the EU-15, with higher speed by the new member states. However, the existence of beta convergence in the sub-periods 1993-2000 and 2009-2015 has not been confirmed.

Meksi and Xhaja (2017) have found that WB countries have had higher growth rates, but slower convergence compared to the new member states. The global crisis caused lower growth rates after 2009 that increased the gap of the WB relative to the EU. Within the beta concept of convergence, they have found faster beta convergence in the WB countries than in new member states (all 13 countries of the EU enlargement since 2004), which confirms that less developed economies with lower initial level of GDP per capita, have increased at a faster pace than more developed transition economies. Within sigma concept, they have found that the income dispersion relative to the EU has diminished within the period 1995-2015. They extended their analysis by sectoral convergence and concluded that the economic structure lags behind the EU in productivity terms, as experienced in the agricultural sector.

This paper will enrich the empirical literature on convergence of the WB countries to the EU, providing a contribution especially on the linkages between nominal and real convergence as complementary processes, as well as the importance of macroeconomic policy mix for the convergence, on the case of the WB region.

\section{Stylized facts on real convergence}

The real convergence of the WB countries is measured by the percentage of GDP per capita at purchasing power parity (PPP) relative to the EU average. The latest available data for 2016 showed that WB countries ranged between $30 \%$ (in Albania) to $42 \%$ (in Montenegro) of the average level of GDP per capita at PPP in the EU. The range of the WB countries is much lower compared to the range of the three last countries that joined the EU which is from $48 \%$ (in Bulgaria) to $59 \%$ (in Romania and Croatia) in 2016. The level of real convergence of the WB in 2016 is only comparable to the convergence of the Bulgaria and Romania after the entrance in the EU (35\% for Romania and 37\% for Bulgaria) in 2005. Afterwards, both countries intensified their real convergence to the EU average, which is in line with the arguments that the EU entrance provides additional support to the growth and convergence, considering the benefits of the economic union as well as positive perceptions of the investors about the countries' prospects. 
Graph 1: Real convergence of WB to EU

GDP p.c. at PPP of the WB countries as \% of the EU average

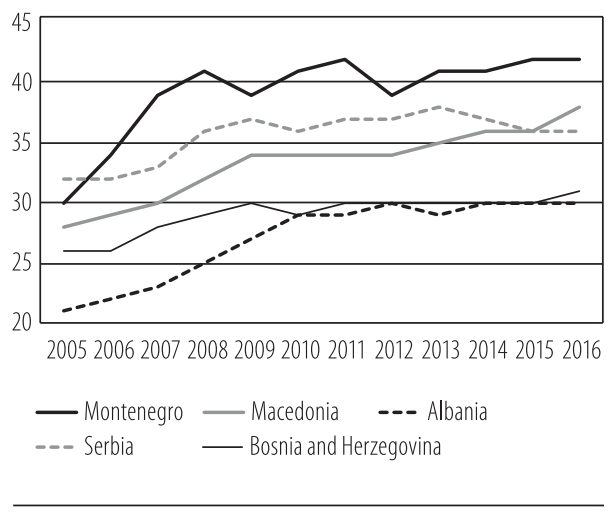

Source: Eurostat
Graph 2: Real convergence of new member states (NMS)

GDP p.c. at PPP of the New member states as \% of EU average

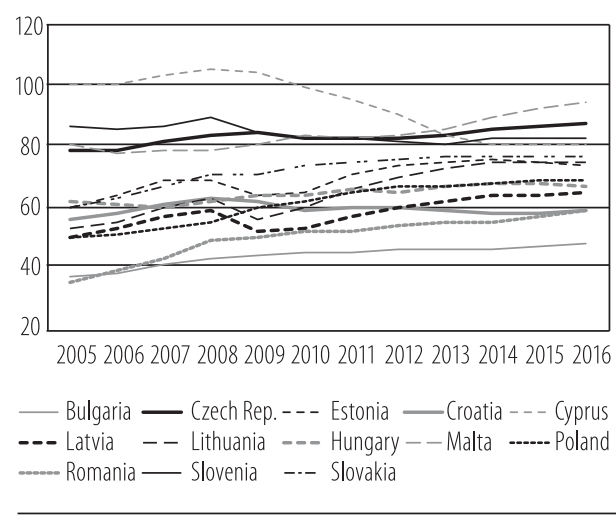

Source: Eurostat

The analysis of real convergence in the period before and after the global crisis points to the difference in convergence dynamics with slowdown of the average convergence, which halved from 5.2 p.p. prior to the crisis to 2.8 p.p. during the crisis (Chart 3), besides the economic slump that the crisis caused to the EU economy. In three of the analysed WB economies there is a faster catch up in the pre-crisis period than after the crisis (Montenegro, Serbia, and Bosnia and Herzegovina). In Macedonia and Albania the dynamics is opposite - faster during the global crisis, while in Serbia there was stagnation in real convergence during the crisis. The real convergence dynamics also halved during the crisis within the new member states (13 countries) from 6.3 p.p. to 3.6 p.p. although four of them have shown faster convergence dynamics during the crisis (Lithuania, Hungary, Malta, and Poland) in a situation of weaker economic performances of the core member states. 
Graph 3: Change in the level of real convergence

Change in the level of real convergence (in p.p.)

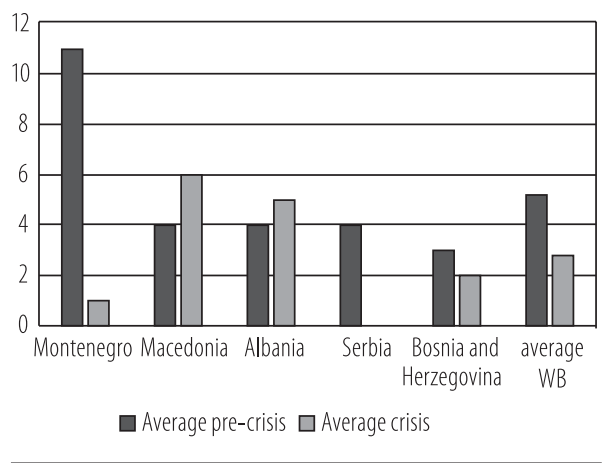

Source: Author's calculations.
Graph 4: Catch up rate in real convergence

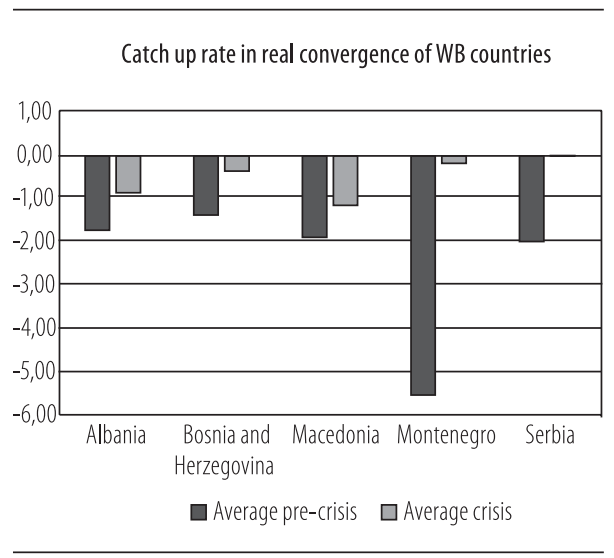

Source: Author's calculations.

Regarding real convergence, it is interesting to take a look at the catch up rate of WB. The catch up rate, in line with Halmai and Vasary (2010) is calculated as:

$\mathrm{CR}=100 * \Delta\left(\mathrm{y}_{\mathrm{it}}-\mathrm{y}_{\mathrm{t}}^{*}\right) /\left(\mathrm{y}_{\mathrm{it}}-\mathrm{y}_{\mathrm{t}-1}^{*}\right)$

where $y$ is GDP per capita at PPP for country $i$ at time $t, y^{\star}$ is the weighted average for the EU, $\Delta$ is the difference between $t$ and $t-1$. In case of a negative catch up rate, the disparity relative to the EU average decreases and vice versa.

It is worth to note that the catch up rate in all WB countries (Chart 4) during the crisis was slower than in the pre-crisis, however, it remained negative pointing to further reduction of the negative gap to the EU, except in the case of Serbia.

\section{Stylized facts on nominal convergence and main macroeconomic indicators relative to EU benchmarks}

Furthermore, the nominal convergence has been observed, considering its importance for the real convergence. The Optimal currency area theory points to the need of real convergence as a prerequisite for economic synchronization within or towards the currency union. The Maastricht criteria for the euro area refer to the several indicators of economic convergence (inflation, budget deficit, public debt, interest rates, and exchange rates) as obligatory before joining the euro area. However, it seems that real convergence and nominal convergence are mutually 
reinforcing processes in practice. Nominal convergence usually provides a stable macroeconomic environment as a favourable floor for real convergence. On the other hand, real convergence means reducing exposure to asymmetric shocks and, therefore, facilitates nominal convergence.

In continuation, we explore the level of nominal convergence of the WB economies and discuss its importance for the real convergence. The nominal convergence will be assessed through some of the main Maastricht indicators, with their pre-defined threshold. In addition, in order to capture different aspects of convergence in macroeconomic indicators, some of the indicators of the Macroeconomic imbalances procedure (MIP) of the European Commission ${ }^{2}$ are used, with their pre-defined thresholds.

\section{Graph 5: Budget deficit gap}

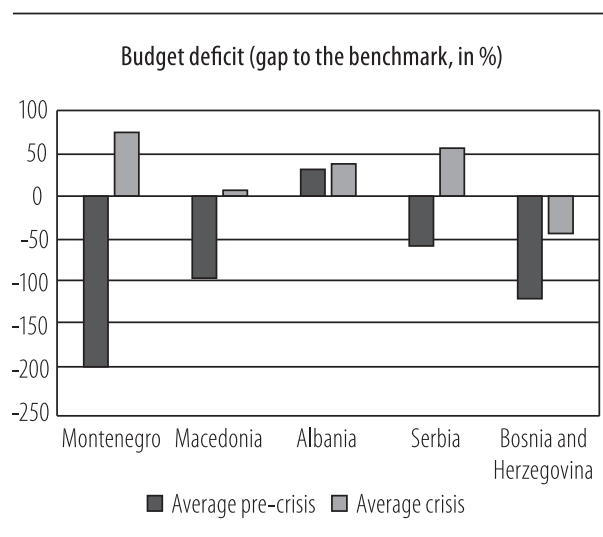

Source: Author's calculations.

\section{Graph 6: Public debt gap}

Public debt (gap to the benchmark, in \%)

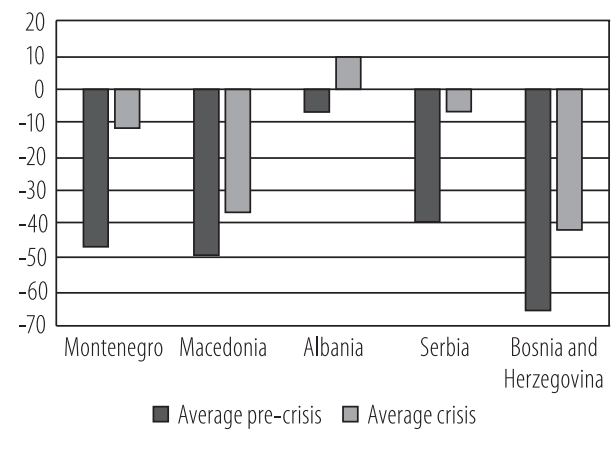

Source: Author's calculations.

The budget deficit is assessed relative to the Maastricht limit of 3\% of GDP, across the analysed period 2005-2016. Regarding this indicator, the WB countries have shown different performances across the time. However, the general tendency in the pre-crisis period (up to 2008) was approaching to the limit, with the exception of Albania that was already above the benchmark. During the crisis, the room relative to budget deficit benchmark was exhausted in most of the countries, therefore, all countries have shown some overshooting, excluding Bosnia and Herzegovina. This is in line with countercyclical fiscal policies of these countries during the crisis, aimed at supporting economic recovery. However, some of the countries have shown first signs of fiscal consolidation (Serbia, Macedonia).

\footnotetext{
2 Source: Alert Mechanism Report, European Commission, February 2012.
} 
The public debt is observed relative to the Maastricht limit of $60 \%$ of GDP (although literature and practice are already pointing to even lower limits for emerging economies). In the period prior of the global crisis, all the countries were below the limit and Albania was the closest to the limit. During the crisis, all the countries had been reducing that gap and Albania surpassed the benchmark. The increase of the public debt was in line with the expansionary fiscal policy during the crisis. Bosnia and Herzegovina and Macedonia were still well below the limit in 2016 .

Although the inflation benchmark is available within the Maastricht criteria, it is defined on fluctuating basis (no more than 1.5\% above the rate for the three EU member states with the lowest inflation over the previous year), opposite to the previous two indicators given as fixed benchmarks. In order to avoid these fluctuations and to take care of different structure of the inflation index in the WB countries compared to the EU member states (which could be very relevant in a situation when inflation is driven by fluctuations of the main commodity prices), we decided to use a fixed benchmark for inflation of $2 \%$, which is the medium term price objective of the ECB. In this framework, it is observed that all WB countries were over the inflation limit prior to the crisis, with largest overshooting in Serbia and lowest in Albania. During the crisis, in line with general decline in the world commodity prices, Bosnia and Herzegovina, Macedonia, and Montenegro were below the limit, on average, while Albania remained slightly above the limit and Serbia significantly reduced the overshooting. Krstevska (2015) noted that central banks in emerging economies, including SEE countries, were gradually reducing the interest rate during the crisis and also took specific measures aimed at supporting recovery.

Graph 7: Inflation gap

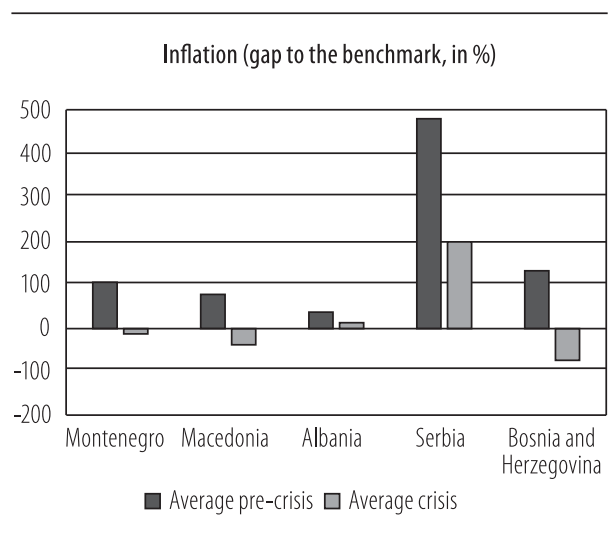

Source: Author's calculations.

\section{Graph 8: Current account deficit gap}

Current account deficit (gap to the benchmark, in \%)

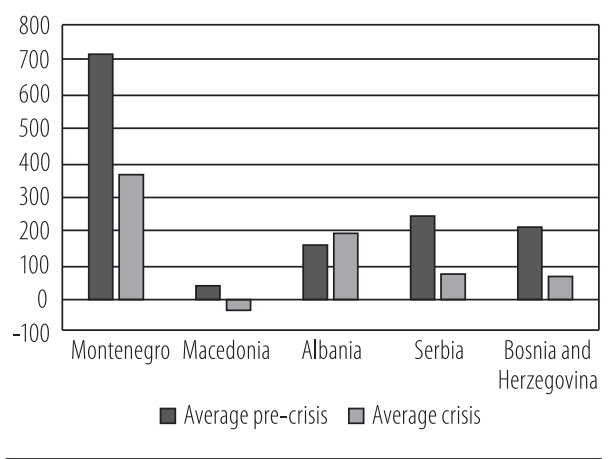

Source: Author's calculations. 
For the needs of this paper, the external position is observed by the current account deficit and as a benchmark is used the lower limit according to MIP of the European Commission of -4\% of GDP. Relative to this limit, all WB economies performed above the benchmark in the pre-crisis period, with smallest misalignment in Macedonia. On the other hand, during the crisis, four countries on average reduced the current account deficit (except Albania) and Macedonia was even slightly below the benchmark. The shrinking in the current account deficit in most of the countries during the crisis reflected the weaker economic growth and also price impact on the import of commodity goods, in line with favourable world market developments.

Unemployment is also assessed against the benchmark within the MIP, which is $10 \%$ (although over a three-year horizon). Regarding this indicator, all WB countries are above this limit in both sub-periods, with Bosnia and Herzegovina and Macedonia having largest misalignment in both sub-periods. It is worth noting that, in Bosnia and Herzegovina, Macedonia and Montenegro further approached to the limit during the crisis (reduction in unemployment), while opposite movement was recorded in the remaining two countries.

\section{Graph 9: Unemployment gap}

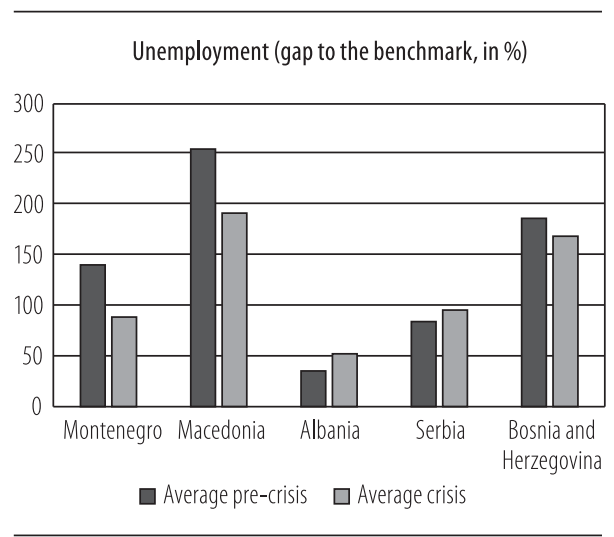

Source: Author's calculations.
Graph 10: Credits to GDP ratio gap

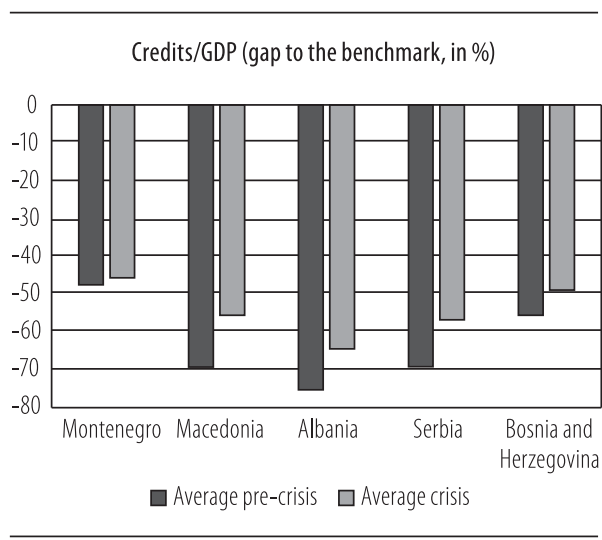

Source: Author's calculations.

Finally, financial intermediation is observed through the ratio of the banks' private sector credits to $\mathrm{GDP}^{3}$, where the average of this ratio in $\mathrm{EU}$ in the period $2004-2016$ is used as the benchmark, which is $106.3 \%$. The period is set to capture both pre-crisis and crisis periods, as well as the EU enlargement in 2004 (and later), considering that the new Member States have more similar features with

3 Within MIP, the limit for this indicator is given only for the annual flow. 
the $\mathrm{WB}$ region regarding financial intermediation than the core member states. Within this framework, the analysis has confirmed that all WB economies are significantly below this benchmark in both sub-periods. However, all countries moved upward in approaching the benchmark during the crisis, with the smallest change in Montenegro and Bosnia and Herzegovina, while the biggest change was in Macedonia.

Besides establishing sound macroeconomic policy mix, in the process of transforming the economies, the WB countries have been doing large structural reforms, aiming at boosting productivity and competitiveness. The global competitiveness index of the World economic forum is a wide spread measure of the competitiveness, that captures different aspects of the competitive position of the countries. According to the global competitiveness index 2015-16, Sanfey et al. (2016) noted that the average ranking of the WB (86) is far behind the ranking of the EU (36), with ranking of Macedonia (60) being closest and the ranking of Bosnia and Herzegovina (111) being the most distant from the EU ranking. However, it is worth to note that all WB countries recorded evolution in the score within this index, therefore in the period 2015-16 the average score for WB increased by 0.31 compared to the period 2007-08, while the average score for the EU increased only for 0.03 , pointing to the convergence of this region in terms of competitiveness. Between the WB countries, the highest increase in the score is measured in Macedonia (0.55) and the lowest in Serbia (0.10) and Bosnia and Herzegovina (0.15).

It is very important to point out that the benchmarks used in this analysis are considered as rules of thumb that are generally accepted as reasonable, although they may not be always the most suitable (considering the development stage of some of analysed countries). Therefore, that could be an additional explanation especially for the indicators where larger gaps exist. However, maintaining disciplined macroeconomic policies and implementing structural reforms should be in favour of stable market expectations, stronger investment and consumer confidence, all together supporting economic growth and real convergence.

\section{Data and methodology}

The usual approach in the convergence analysis is to assess the so-called Beta and Sigma convergence. Beta convergence (Barro and Sala-I-Martin, 1992) refers to absolute convergence of individual countries, according to the following equation: 
$\operatorname{Ln}\left(\mathrm{Y}_{\mathrm{it}} / \mathrm{Y}_{\mathrm{i} 0}\right)=\alpha+\beta \ln \left(\mathrm{Y}_{\mathrm{i} 0}\right)+\alpha$

where $\mathrm{Y}$ is GDP per capita, $\mathrm{i}$ is the individual country, 0 is the initial year, $t$ is the final year, $n$ is the number of years, and $\ln$ stands for natural logarithm. If $\beta$ coefficient is negative and significant, there is an absolute convergence.

The sigma convergence is a measure of relative convergence, in our case compared to EU, by investigating the evolution over time of some dispersion measures of the relevant economic variables (Marelli and Signorelli, 2015).

In addition to beta and sigma convergence, this work includes assessment of the importance of the nominal convergence and convergence in the main macroeconomic indicators for the real convergence relative to EU. For this purpose, the percentage gaps to different benchmarks for the included variables (as explained above) have been used as independent variables. The dependent variable in the equation is the percentage gap in the real convergence measured through GDP per capita at PPP relative to EU average (ygap), while the explanatory variables are: the percentage gap relative to the benchmarks for the budget deficit, public debt, inflation, unemployment, current account deficit and private sector credits/ GDP.

$\mathrm{y}_{\text {gap }}=\mathrm{a}+\mathrm{b}_{\mathrm{gap}} \mathbf{x}+\ldots+\varepsilon$

Our panel data refers to five WB countries for the period 2005-2016 and data in this paper are provided from the Eurostat, World Bank and IMF databases, as well as from the relevant national institutions. The analysed period was labelled by diversified economic performances of the analysed countries and therefore different progress in the nominal and real convergence to the EU. Thus, it was quite reasonable to expect the non-stationarity in the data ${ }^{4}$, referring to the need of use of the panel cointegration techniques. The cointegration was confirmed by using the Pedroni test (Pedroni, 1999), which allows for heterogeneity in both dynamics and error variance in the panel. ${ }^{5}$ Between the available estimation techniques for the panel cointegration, we used the fully modified ordinary least squares (FMOLS), which proved to be more flexible compared to the dynamic OLS (DOLS), and suffers much less from small sample size distortion (Pedroni, 2000).

4 The unit root test could be provided on request.

5 The results of this test could be provided on request. 


\section{Results and discussion}

Following the approach of the reviewed literature, the beta and sigma convergence for the WB countries have been estimated in order to assess their absolute convergence to the developed world and relative convergence to the EU. The beta coefficient has been estimated according to the usual regression of the natural logarithm of GDP per capita in the initial year (2000) on the average annual growth rate in the overall analysed period 2000-2016 and also for the period before the crisis (2000-08), as well as after the crisis (2009-16) when using the natural logarithm of GDP per capita in 2009 as initial year. The results are presented in Table 1 and they showed that there is an absolute convergence of this region relative to the developed economies, considering a negative and significant beta coefficient of -3.87 for the overall period. Looking into the sub-periods, there was a much stronger absolute convergence up to 2008, with beta coefficient of -9.93 , pointing to the faster convergence considering lower initial growth at the earlier stages of transition, as well as the global economic expansion prior to the crisis. On the other hand, during the global crisis, there has been a continuation of convergence but at much slower pace, with a negative beta coefficient of -3.16. Beta coefficients for both sub-periods are significant.

Table 1: Results for beta coefficients

\begin{tabular}{lccc}
\hline & $2000-16$ & $2000-08$ & $2009-16$ \\
\hline Beta coefficient & $-3,87$ & $-9,93$ & $-3,16$ \\
\hline p-value & 0,03 & 0,09 & 0,096 \\
\hline R-squared & 0,24 & 0,24 & 0,25 \\
\hline
\end{tabular}

* Estimations are done in E-views 8.

Sigma approach measures the relative dispersion of the convergence within the $\mathrm{WB}$ region towards the EU. Considering developments of the average rate of convergence of GDP p.c. at PPP, it was faster in the period prior to the global crisis, while afterwards there has been stagnation. Dispersion is assessed through the standard deviation of the GDP convergence rate across the time in the region and it points to growing disparity before the crisis (larger discrepancies between the countries in the convergence terms due to different growth pace), however, the disparities decreased during the crisis due to the crisis impact and the general slowdown in the growth pace in the region.

For comparison, after the stagnation of real convergence in the acute stage of the crisis, the new EU member states have further intensified the real convergence, 
taking the advantage of crisis impact over core EU members and adding positively to the average GDP p.c. at PPP of the EU. The real convergence in the crisis is more intensive in the new member states than in the $\mathrm{WB}$, which is in line with the findings by Stanisic (2016). At the same time, despite larger disparities in the real convergence between new members states after the EU enlargement (in line with findings by Halmai and Vasary (2010)), they have reduced during the crisis.

\section{Graph 11: Average convergence and dispersion of WB}

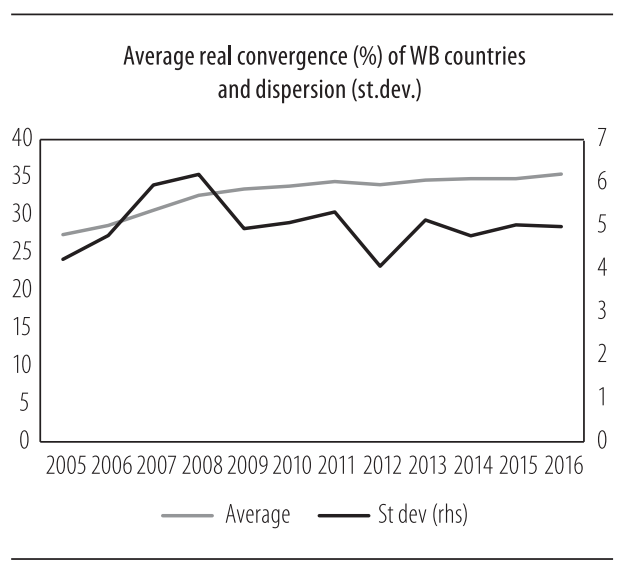

\section{Graph 12: Average convergence and dispersion - NMS}

Average real convergence (\%) of the New member states and dispesion (st.dev.)

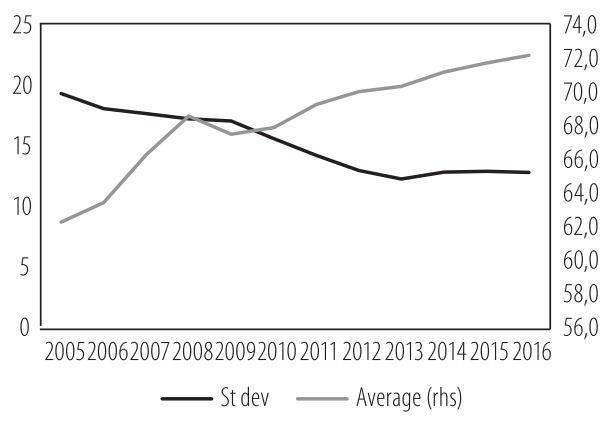

This paper will additionally test the significance of nominal convergence and convergence in the (other) main macroeconomic indicators for the real convergence process. This is done by estimating if the real convergence in view of the gap in GDP per capita relative to the EU average is dependent on the fluctuations in the gaps regarding the benchmarks (as analysed above) in the unemployment, budget deficit, public debt, inflation, current account deficit, and private sector credits to GDP ratio. As already explained, the estimation was done by using FMOLS and the results are given in Table 2. They have shown that approaching the benchmark for credits is in favour of stronger real convergence, confirming the importance of credit support for economic growth dynamics. The reduction of the distance to the benchmark for the budget deficit also supports the real convergence, probably pointing to the importance of the fiscal multipliers. In addition, approaching the benchmark for the public debt is also supportive for the real convergence. 
Table 2: Results from FMOLS (dependent variable: GDP p.c. at PPP, gap)

\begin{tabular}{lcc}
\hline & $2005-16$ & $2009-16$ \\
\hline Unemployment (gap) & $-0,025$ & $0,079^{*}$ \\
\hline Budget deficit (gap) & $0,008^{* *}$ & $0,021^{*}$ \\
\hline Public debt (gap) & $0,156^{*}$ & $0,108^{*}$ \\
\hline Inflation (gap) & 0,006 & $0,017^{*}$ \\
\hline Current account deficit (gap) & 0,004 & $0,001^{* *}$ \\
\hline Credits / GDP (gap) & $0,412^{*}$ & $0,267^{*}$ \\
\hline
\end{tabular}

* significant at $100 \%,{ }^{* *}$ significant at $95 \%$ and ${ }^{* * *}$ significant at $90 \%$ confidence interval.

The estimation that is done only for the crisis period confirmed the credits to GDP ratio and budget deficit as important factors for the real convergence, which have the same sign and they are both significant. However, the coefficient for credits is lower and coefficient for budget deficit is higher, pointing to the slowdown of the credit growth during the crisis and the smaller (used) room for fiscal stimulus of the economic growth, and therefore of the real convergence. However, the sign of the public debt changed pointing to the higher distance from the benchmark which, although positive in short run, is signalling risks in this area when it is long-lasting. Additionally, the other variables in this estimation are also significant. The approaching to the unemployment benchmark and to the benchmark for the current account deficit positively affected the real convergence during the crisis. It is interesting that moving away from the inflation benchmark (on lower side) in the crisis period also positively affected the real convergence that could be explained by low commodity prices during the crisis that stimulated both demand and growth.

\section{Conclusions}

The WB countries throughout the transition period have been gradually converging to the EU. However, due to different reasons, including transitional issues, macroeconomic factors as well as internal and external shocks, the real convergence of the $\mathrm{WB}$ region to the EU average is relatively slow. The last global crisis created a specific environment for the convergence process of the WB economies. The latest available data showed that the convergence of the WB countries to the average level of GDP per capita at PPP in the EU is still rather low and it is only comparable to the level of convergence of some less developed new Member States after their entrance in the EU. The analysis of real convergence in the period before and after the global crisis points to differences in the convergence dynamics with a slowdown of the average convergence which halved during the crisis, in addition to economic slump that the crisis caused to the EU economy. 
In practice, it seems that real and nominal convergences are mutually reinforcing processes. Nominal convergence usually provides a stable macroeconomic environment as a favourable floor for real convergence. On the other hand, real convergence means reducing exposure to asymmetric shocks and, therefore, facilitates nominal convergence. Therefore, we explored the level of nominal convergence of the WB economies as well as the convergence in (other) main macroeconomic indicators and discuss their importance for the real convergence. The nominal convergence has been assessed through some of the main Maastricht indicators, as well as by using some of the indicators of the Macroeconomic imbalances procedure of the European Commission, all with their pre-defined thresholds, in order to capture different aspect of nominal convergence. The benchmarks used in this analysis are considered as rules of thumb that are generally accepted as reasonable, although they may not be always the most suitable (considering the development stage of some of analysed countries), that could be an additional explanation especially for the indicators where larger gaps exist. However, maintaining disciplined macroeconomic policies and implementing structural reforms should be in favour of stable market expectations, stronger investment and consumer confidence, and all together will support the economic growth and real convergence.

The empirical assessment of importance of changes in the gaps of the nominal convergence indicators and other main macroeconomic indicators for the real convergence has shown that reducing the gap in the financial intermediation was an important driver of growth and real convergence in the overall analysed period and during the crisis. During the crisis, a reduction of the gap in unemployment and current account deficits were additional drivers of real convergence. In addition, the crisis period proved that making a distance from the benchmarks of budget deficit (above) and inflation (below) was supportive for the real convergence and growth, although in the case of inflation this is probably due to the lower commodity prices. Finally, although expanding budget deficit and public debt could be supportive to the real convergence during a crisis (due to fiscal multipliers), there are risks that it could generate negative impact if the expanding is long-lasting.

Having in mind these findings, there is an obvious linkage among economic, nominal, and real convergences to the EU in the case of the WB countries. The convergence is a dynamic process and there is a need to take care of its sustainability over time. Maintaining the nominal convergence indicators on a sustainable level or orienting them to the generally accepted levels within the EU is supportive of accelerated growth and enhancement of real convergence. 


\section{References}

1. Barro R. J., Sala-i-Martin X. (1992). Convergence, Journal of Political Economy, Volume 100, No. 2;

2. Bastidon C., Gilles P., Huchet N. (2016). The ECB, between conservatism and pragmatism, Journal of Central Banking Theory and Practice, Vol. 5 No.1, p 25-52;

3. Halmai P., Vásáry V. (2010). Real convergence in the new Member States of the European Union (Shorter and longer term prospects), The European Journal of Comparative Economics, Vol. 7, n. 1, p. 229-253;

4. Krstevska A. (2015). The monetary policy objectives during the crisis: an overview of selected Southeastern European countries, Journal of Central Banking Theory and Practice, Vol. 4 No.1, January 2015, p.35-46;

5. Marelli E. and Signorelli M. (2015). Convergence, Crisis and Unemployment in Europe: The Need for Innovative Policies, Croatian Economic Survey: Vol. 17, No. 2, December 2015, p. 5-56;

6. Meksi E. and Xhaja (Gjika) E. (2017). Income and structural convergence of Western Balkans to European Union, European Journal of Comparative economics, Vol.14, n.1, p. 141-154;

7. Sanfey P., Milatović J. and Krešić A. (2016). How the Western Balkans can catch up?, EBRD Working paper No. 186.

8. Shehovic D. (2015). Analysis of fiscal rules in the European Monetary Union, Journal of Central Banking Theory and Practice, 2015, Vol. 4, No. 1, p. 19-33;

9. Stanisic N. (2016). Income convergence in the process of the Western Balkan states' accession to the EU, Economic Horizons, January - April 2016, Volume 18, Number 1, p. 3 - 15;

10. Pedroni P. (2000). Fully Modified OLS for Heterogeneous Cointegrated Panels, Nonstationary Panels, Panel Cointegration and Dynamic Panels, Volume 15, p. 93-130, Elsevier Science Inc. 